\title{
To See What You Cannot See
}

\author{
Lars B.Bååth ${ }^{1}$ \\ ${ }^{1}$ Halmstad University \\ Box 823 \\ S-301 18 Halmstad, Sweden
}

\begin{abstract}
This paper discusses imaging with complex data from micro-wave, mm-wave, and optical interferometers. An overview of methods to extract physical parameters as images from interferometer data is made and two- and three-dimensional images of gas flows, quasi-stellar objects, steel melts, and fiber material such as wood are presented.
\end{abstract}

\section{References}

Kaestner, A.: Ph.D. Thesis Chalmers University of Technology (2002)

Bååth,L.B.: Mapping in practice In: Very Long Baseline Interferometry: Techniques and Applications, eds. Felli and Spencer, NATO ASI Series (1989) p199

Bååth,L.B., Padin,S., Woody,D., Rogers,A.E.E., Wright,M.C.H., Zensus,A., Kus,A.J., Backer,D.C., Booth,R.S., Carlstrom,J.E., Dickman,R.L., Eemrson,D.T., Hirabyashi,H., Hodges,M.W., Inoue,M., Moran,J.M., Morimoto,M., Payne,J., Plambeck,R.L., Predmore,C.R., Rönnäng,B.: The Microarcsecond Structure of $3 \mathrm{C} 273$ at $3 \mathrm{~mm}$ In: Astron.Astrophys., V241 (1991) L1

Okopi,J. and Bååth,L.B.: On the development of a computer aided system for visualization of 3D flow structures In: Visualization in Engineering and Sciences, Luleå (1991)

Bååth,L.B., Tilmaz,J., Kaestner,A., and Silverberg,P.: Imaging with Interferometers In SSAB (1998)

Kaestner,A.. and Bååth,L.B.: Microwave polarimetry based wood scanning In: 12th International Symposium on Nondestructive Testing of Wood, Sopron, Hungary (2000)

Malmberg,D., Malm, J., and Bååth,L.B.: Waste gas analysis with microwave technology In: Oxygen in Steelmaking: towards cleaner steel, London (2001) 